September 2015 Vol.:3, Issue:2

(c) All rights are reserved by Goonewardene et al.

\title{
Penile Grafting for Benign Causes: An Analysis of Patient Outcomes
}

\begin{abstract}
Keywords: Penile grafting; Benign pathology; Patient outc ome Abstract

Introduction: Common conditions such as lichen sclerosis [1] and Peyronie's disease result in impaiment of sexual function. This can be contributed to by lack of penile skin (lichen sclerosis) or involvement of the tunic a albuginea (Peyronie's disease) [2]. New grafting techniques maintain penile length and function.
\end{abstract}

Materials and methods: Over a three year period 11 cases undergoing penile reconstruction were reviewed, with a 36 month follow-up period. We examine underlying pathology, cosmesis outc omes including graft ta ke and patient satisfaction, sexual function and complications.

Results: Out of the 11 patients, 4 cases required grafting, 3 were full thickness skin grafts (shaft defect) with one split skin graft (glans defect). $100 \%$ of patients were cosmetically satisfied both grafted, and none grafted. $100 \%$ of grafts had good take, none were rejected. $25 \%$ of grafted patients and $28 \%$ of none grafted patients had erectile dysfunction (IIEF <20) [3]. There was minimal loss of penile length. 100\% were satisfied with the outcome of the procedure. Complications included meatal stenosis in $50 \%$ of grafted patients. This is either due to surgery or pre-existing disease. One patient required an additiona procedure of scrotal debulking. There were no contractures.

Discussion and conclusion: For cases of benign pathology, penile grafting does result in patient satisfaction with good overall cosmesis and erectile function. Good outcomes depend on having an experienced specialist surgeon and team who are able to handle complic ations when they a rise.

\section{Introduction}

There have been a number of articles recently on skin grafting for malignant penile disease. However, there have been none addressing benign penile grafting. Common conditions such as lichen sclerosis [1] and Peyronie's disease result in impairment of sexual function. This can be contributed to by lack of penile skin (lichen sclerosis) or involvement of the tunica albuginea (Peyronie's disease) [2]. There is also the risk of squamous cell carcinoma related to lichen sclerosis [4]. Surgical intervention for benign penile lesions may sometimes require radical excision and grafting. New grafting techniques maintain penile length and function. We present results of our three year series focusing on outcomes in patients undergoing penile grafting for benign causes.

\section{Methods}

We (retrospectively reviewed records of 11 patients who presented to Plymouth hospitals during the years 2010-2013. All were operated on by a single surgeon (RP). The cases requiring penile reconstruction were reviewed. Patients were followed up for an average of 12 months (range 2-36 months). The surgical technique used involved a circumcision if not performed previously, before degloving the penile skin to the base of the penis. The affected area was

\section{Journal of}

Andrology \& Gynaecology

\section{Goonewardene $\mathrm{SS}^{1 *}$ and Pearcy $\mathrm{R}^{2}$}

${ }^{1}$ Great Western Hospitals, Marlborough Rd, Swindon, Wiltshire SN3 $6 B B, U K$

${ }^{2}$ Plymouth Hospitals, NHS Trust, Derriford Rd, Crownhill, Plymouth, Devon PL6 8DH, UK

\section{*Address for Correspondence}

Goonewardene SS, Great Western Hospitals, Marlborough Rd, Swindon, Wiltshire SN3 6BB, UK, E-mail: ssg7727@yahoo.co.uk

Submission: 04 August, 2015

Accepted: 10 September, 2015

Published: 15 September, 2015

Copyright: (c) 2015 Goonewardene SS, et al. This is an open access article distributed under the Creative Commons Attribution License, which permits unrestricted use, distribution, and reproduction in any medium, provided the original work is properly cited.

Reviewed \& Approved by: Dr. Ehab Eltahawy, Associate Professor of Reconstructive and Endourology Division, University of Arkansas for Medical Sciences, USA

excised. Grafting of porcine collagen (Surgisis by Cook) was applied to the tunica albuginea as described by Lue [5]. Stretched penile length was used to measure graft application. Split thickness skin grafts were applied to glans/coronal defects. Full thickness skin grafts were used for shaft defects (Please see Figures). The amount of skin used was calculated according to the stretched penile length. Patient

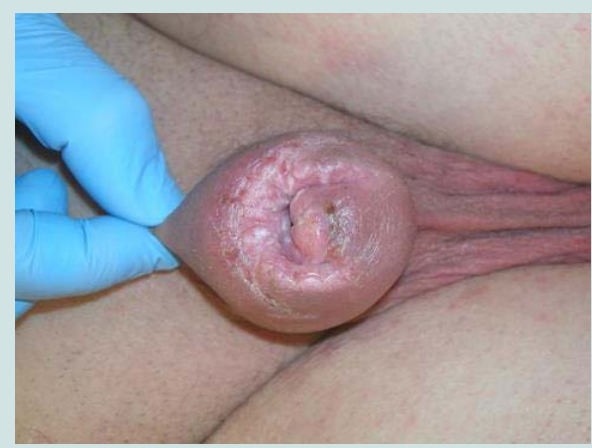

Figure 1: Balanitis xerotica obliterans

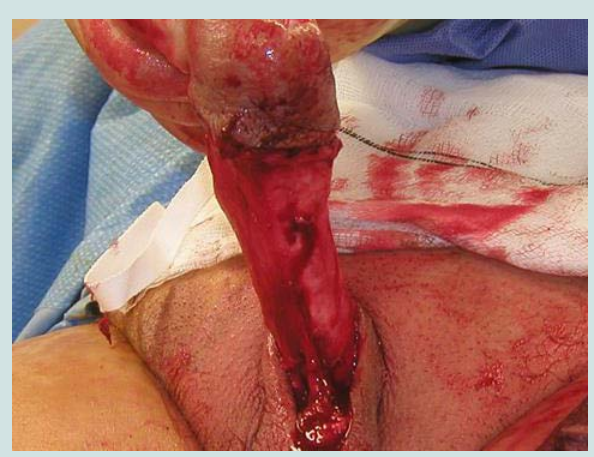

Figure 2: Circumferential skin insicion and degloving to base of penis. 


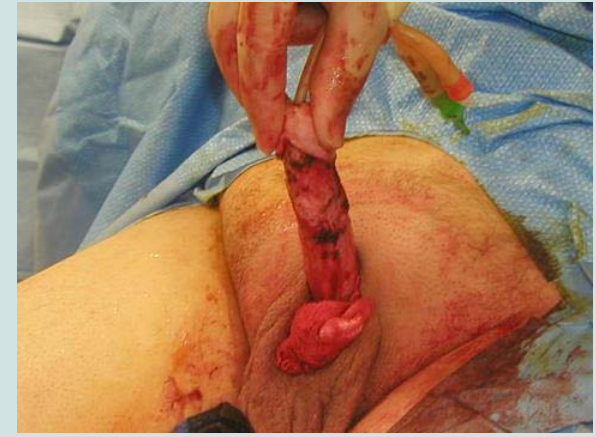

Figure 3: Excision of affected area.

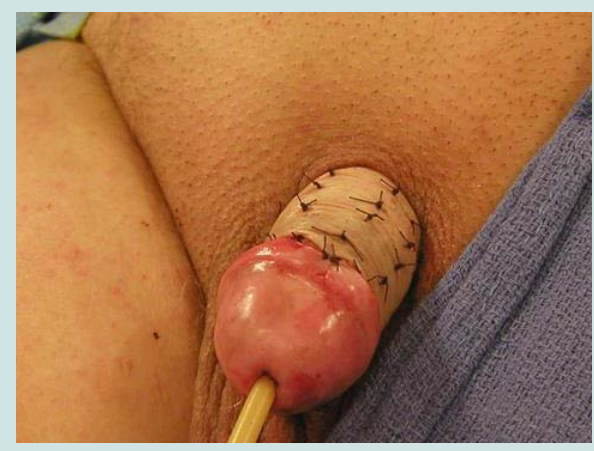

Figure 4: End result post graft application.

outcomes were examined including underlying pathology, comesis outcomes (including graft take and patient satisfaction), sexual function and complications. Subjective parameters were used for patient satisfaction with cosmesis. There was no loss in penile length. Sexual function was measured via IIEF scores. In those patients where skin grafting had been used standard protocol for genital skin graft management was used. ( $24 \mathrm{hrs}$ bed rest was followed by slow mobilisation with review and change of dressings at 7-10 days and penile stretching). All patients receive Cialis (tadalafil) $5 \mathrm{mg}$ OD which may increase penile blood flow and reduce post operative erectile dysfunction [6]. Patients who were not grafted were also included to give a comparison to grafted patients for outcomes.

\section{Results}

There were 11 cases reviewed. 4 cases required Lue procedure and grafting. The average age was 58 (range 48-69 years). One involved lichen sclerosis, the other 3 involved Peyronies disease. All patients had reasonable erectile function (IIEF $>20$ ) and reasonable good skin conditions pre-operatively. $100 \%$ were cosmetically satisfied. $100 \%$ of grafts had good take, no re-grafting was required. There was minimal loss of penile length. Only one case had a loss of $0.5 \mathrm{~cm}$. There was no contractures post operatively. $100 \%$ of patients were satisfied with the outcome of the procedure. Post-operative complications included $25 \%$ of grafted patients and $28 \%$ of none grafted patients had erectile dysfunction $($ IIEF < 20) [3]. These were successfully treated on Cialis/ Viagra. Meatal stenosis occurred in $50 \%$ of grafted patients. This is either due to surgery or pre-existing diseases. One patient required further scrotal debulking. There were no contractures.

\section{Discussion}

For cases of benign pathology, penile grafting does result in patient satisfaction with good overall cosmesis and erectile function. Despite the progression towards radical surgery, good outcomes depend on having an experienced specialist surgeon and team who are able to handle complications when they arise. It should be remembered the foreskin never grows back and therefore with rare exceptions a redo circumcision should never be performed.

When dealing with a buried penis, surgical technique that can be employed include supra pubic fat pad excision, abdominoplasty, apronectomy, split/full thickness skin graft, division of the suspensory ligament, scrotoplasty and excision of foreskin [7]. However, the success rate of these is debatable.

\section{Conclusion}

For cases of benign pathology, penile grafting may result in patient satisfaction with good overall cosmesis and erectile function. Whilst this is a small series, the overall impression is that good outcomes depend on having an experienced specialist surgeon and team who are able to handle complications when they arise.

\section{References}

1. Luz FB, Ferreira JA, De Azevedo Valle H, Basilio-de-Oliveira CA (1999) HPV em carcinoma verrucoso sobre liquen escleroso do penis [Portuguese]. An Bras Dermatol 74: 253-255.

2. Loreto C, La Rocca G, Anzalone R, Caltabiano R, Vespasiani G, et al. (2014) The role of intrinsic pathway in apoptosis activation and progression in Peyronie's disease. BioMed Res Int 2014: 616149.

3. Rosen RC, Riley A, Wagner G, Osterloh IH, Kirkpatrick J, et al. (1997) The international index of erectile function (IIEF): A multidimensional scale for assessment of erectile dysfunction. Urology 49: 822-830.

4. Michajlowski I, Panek D, Sobjanek M, Michajlowski J, Wlodarkiewicz A (2012) Malignant transformation in patients with penile lichen sclerosus. Transformacja nowotworowa u pacjentow z liszajem twardzinowym pracia [English, Polish]. Przegl Dermatol 99: 390-391.

5. Lue TF, El-Sakka Al (1998) Venous patch graft for Peyronie's disease. Part I: technique. J Urol 160: 2047-2049.

6. Coward RM, Carson CC (2008) Tadalafil in the treatment of erectile dysfunction. Ther Clin Risk Manag 4: 1315-1330.

7. Yap T, Chocolaty M, Amr R, Garaffa G, Christopher N, et al. (2015) Buried penis in adults-presentation, surgical techniques and outcome. J Urol 193: e40. 